\title{
Application of a forest dynamics simulator to inform sustainable biodiversity conservation and grazing management in Australia
}

\author{
$\underline{\text { Michael R. Ngugi }}{ }^{1}$, Daniel B. Botkin ${ }^{2}$ and David Doley ${ }^{3}$ \\ ${ }^{1}$ Queensland Herbarium, Science Delivery, Department of Science, Information Technology, Innovation and \\ the Arts, Queensland Government, Mt Coot-tha Road, Toowong, Queensland 4066, Australia; ${ }^{2}$ Department \\ of Biology, University of Miami, Coral Gables, Florida 33124-0421, USA; ${ }^{3}$ Centre for Mined Land \\ Rehabilitation, Sustainable Minerals Institute, The University of Queensland, Brisbane, Qld 4072, Australia. \\ Email:Michael.ngugi@science.dsitia.qld.gov.au
}

\begin{abstract}
Sustainable use and management of natural resources is now a well-accepted principle, but its implementation continues to elude us. This is partly because of the complex and dynamic nature of ecological systems, interdependence among elements, and the impacts that resource management actions have on the functioning of an ecosystem.

Livestock grazing is the most extensive landuse in Australia, occurring in over $55 \%$ of the continent. In forested landscapes this landuse has been characterised by clearing and/or modification of landscapes through overgrazing and changes to fire regimes, followed by re-growth and increase in density of woody vegetation and associated loss in grazing productivity. Consequently, the Vegetation Management Act 1999, now in place in Queensland, requires the coexistence of conservation of biological diversity and primary production. However, a challenge exists in how to integrate the two outcomes in a sustainable manner.
\end{abstract}

This paper describes a case study application of the Ecosystem Dynamics Simulator (EDS), a forest growth model, as a decision support tool for the integration of sustainable livestock production and conservation of biological diversity at Mt Armour Nature Refuge, in western Queensland. The study was initiated by a request from the landowner for advice on how to manage increasing density of woody vegetation (vegetation thickening) without compromising conservation values.The landholder had expressed concern that the vegetation thickening was impinging on livestock production and was therefore in need of thinning. Thinning of vegetation within this bioregion is regulated by the Regional Vegetation Management Code for Brigalow Belt and New England Tablelands Bioregions, Queensland Government (Code) (DNRM, 2012). Firstly, for thinning to occur, the Code requires a verified crown cover increase or presence of $>250$ immature stems in a 0.25 ha area. Secondly, if thinning occurs, all mature stems should be retained, and including 75 or 125 immature stems per 0.25 ha area depending on vegetation type.

Our objective was to establish: 1) whether density of immature stems met thinning criteria of the Code and; 2) what thinning intensity and fire regimes were necessary to promote a sustainable ecosystem. In examining thinning intensity, the potential risk of loss of biodiversity based on recommended retention rates was also investigated. Working in collaboration with the landholder, data were collected from the property and the landowner's tree removal preference was also recorded. The EDS was used to project long-term changes in tree species composition and diameter size class structure for the uneven-aged mixed species native forests and to explore management scenarios that included the use of alternative thinning scenarios and fire regimes.

The results confirmed: 1) the vegetation on the site was dense enough to be thinned under the current Code and projection indicated thickening is likely to continue if left un-thinned; 2) that the landowner's preferred tree removal intensity was not sustainable and; 3) a thinning intensity based on long-term simulation that considered species composition and stand size structure provided the best compromise outcome. The simulation results also confirmed likely inadequacy in the Code's recommended retention rates for immature stems in the studied vegetation types. Retaining only 75 immature stems $(<20 \mathrm{~cm} \mathrm{dbh})$ appeared to be a high risk option because large trees were few, growth rates were low and sapling recruitment was intermittent and vulnerable to drought related mortality. Consequently, retention of at least 140 immature stems would provide a more resilient stand structure and species composition under the dry growth conditions at the study site. This study demonstrated the valuable role that a vegetation growth dynamics simulator can play in elucidating long-term changes in tree species composition and diameter size structure in support of sustainable environmental management.

Keywords: Decision support, vegetation thickening, sustainable thinning regime 


\section{INTRODUCTION}

Vegetation thickening, the increase in the density of woody vegetation on grazed rangelands, woodlands, and forests, is a well-documented global phenomenon that is often described by other terms including woody plant encroachment, bush or shrub encroachment, woody weed increase, woody re-growth and woody plant proliferation (Gifford and Howden, 2001). This phenomenon has been observed in various ecosystems including arid and semi-arid rangelands in Australia (Witt et al., 2009), grasslands in southwest USA (Scott et al., 2006), forests with fire exclusion in USA (Houghton et al., 2000) and tropical rainforests in South America (Phillips et al., 1998). Increase in vegetation density and tree cover in many parts of Australia is associated with recovery and succession following vegetation clearing and changes in fire and grazing regimes. These changes include reduced frequency, extent and intensity of fire due to reduced fuel load caused by grazing or suppression of fire or episodic regeneration following favorable weather events. Thickening woody cover reduces the development of grassy ground layer, leading to reduced livestock production capacity and potential changes in biodiversity (Witt et al., 2009).

Livestock grazing is the most extensive landuse in Australia accounting for $55 \%$ of the continent (SoE, 2011). This landuse has been characterised by extensive clearing and/or modification of forested ecosystems through overgrazing and changes to fire regimes resulting in environmental damage and loss of biodiversity. Legislation has now been put in place to safeguard conservation of biological diversity within livestock production systems but a long-term solution depends on the ability to integrate the two land use objectives in a sustainable manner. A capacity to simulate vegetation growth dynamics, project the outcomes of alternative management options and assess compromise solutions may provide potential opportunities. Forest growth dynamics models have been successfully used to simulate forest succession of different forest types (Botkin et al., 1972; Shugart, 1984; Botkin, 1993; Ngugi et al., 2013). These models provide a framework for informing sustainable vegetation management.

The objective of this study was to:1) establish whether observed density of immature stems met thinning criteria of the Code or whether the stem density was indeed typical for the represented regional ecosystems; 2) determine how many stems could be removed through thinning if thickening was evident, ensuring a suitable stand structure that would sustain the floristic composition and tree size structure of a typical regional ecosystem; and 3) examine a suitable fire regime to manage vegetation thickening.

\section{METHODS}

\subsection{Study area}

This study was conducted at Mt Armour Nature Refuge, located between the latitudes $26^{\circ} 05^{\prime} \mathrm{S}$ and $26^{\circ} 10^{\prime} \mathrm{S}$, and longitude $148^{\circ} 02^{\prime} \mathrm{E}$ and $148^{\circ} 07^{\prime} \mathrm{E}$, approximately $55 \mathrm{~km}$ to the northeast of Mitchell, Queensland. The 1520 hectares nature refuge was legally declared/gazetted in 2001 through a voluntary conservation agreement. It lies within the Brigalow Belt South Bioregion and protects remnant forested ecosystems with low representation in protected nature reserves. The nature refuge is managed predominantly for conservation and grazing. However over $80 \%$ of the nature refuge area is on steep slopes, hence only the relatively flat valley floors are used for grazing. The climate of the site is subtropical characterized by hot dry summers and cold winters, with annual rainfall of $560 \mathrm{~mm}$. December and January are the hottest months with mean maximum daily temperatures of $33.7^{\circ} \mathrm{C}$ and $34{ }^{\circ} \mathrm{C}$ respectively, while July is the coldest month with mean minimum daily temperature of $2.8^{\circ} \mathrm{C}$ based on 100 years of climate data from Australian Bureau of Meteorology (BOM). The species at the location included, Eucalyptus populnea, Eucalyptus melanophloia, Callitris glaucophylla, Geijera parviflora, Eremophila mitchellii and Capparis loranthifolia.

\subsection{Vegetation Management Code Compliance}

All native vegetation in Queensland that is mapped as remnant under the Vegetation Management Act 1999 (VMA, 1999) is protected from clearing without a permit. The requirements for thinning remnant vegetation in the Brigalow Belt are contained in the Regional Vegetation Management Code for Brigalow Belt and New England Tablelands Bioregions (Code) (DNRM, 2012). Thinning under the Code is defined as selective clearing of vegetation at a locality to restore the floristic composition and range of densities typical of the regional ecosystem. Regional ecosystems are defined as those with communities of vegetation on consistent geology, landform and soil characteristics. A successful application for a thinning permit must meet defined performance requirements. The Code prescribes that thinning can only occur in areas where there has been demonstrated thickening or the density of immature trees is greater than 250 stems in a 50 metre x 50 metre ( 0.25 hectare) plot. Additionally, all mature trees, as defined by a species and diameter threshold must be retained. The lower diameter threshold for mature stems of Eucalyptus, Corymbia, Angophora, Lophostemon 
is $30 \mathrm{~cm} \mathrm{dbh}$ and $20 \mathrm{~cm} \mathrm{dbh}$ for other genera. The minimum numbers of immature stems that must be retained during thinning in a 0.25 ha area are defined by the structural category of regional ecosystems that occur on the area to be thinned. These are 125,75 and 50 stems respectively in mid-dense, sparse and very sparse associations.

\subsection{Overview of EDS and parameters}

Ecosystem Dynamics Simulator (EDS) is a non-spatial computer model of forest growth dynamics adapted from the JABOWA-II model (Botkin, 1993). This model characterizes the tree growth process as the relationship between photosynthesis and respiration and as driven by soil water availability, light, availability of nutrients, temperature and competition among trees. Since a forest is constantly changing in stem density, species composition and age structure, the development of these elements is obtained by simulating establishment, growth and death of individual trees. EDS has been adapted, validated (Ngugi and Botkin, 2011; Ngugi et al., 2013) and enhanced with modules for fire intensity and regime impacts, biomass estimation and statistical output to address uneven-aged mixed species forests growing in Australia (Ngugi et al., 2007; Ngugi et al., 2013). Forest gap models have been used widely to simulate the succession of mixedspecies forests in changing environments (Porte and Bartelink, 2002; Shugart, 2002) and their structure is well understood (Shugart, 1984; Botkin, 1993). These models can be parameterised using relatively simple measurements and observations that define optimal growth attributes of each species, and plot characteristics that include soil information, local climatic attributes, and individual tree measurements (species and dbh) (Botkin, 1993).

EDS had been validated in a previous study in the same geographical region and most of the species observed at the study location had been parameterised (Ngugi et al., 2013). The required species information include maximum age, diameter and height, annual diameter increment, annual recruitment estimates, maximum growing degree days for southern and northern limits of a species' geographical distribution, and tolerance of shade, drought and waterlogging.

\subsection{Field data collection}

Intensive field data collection was conducted on five $50 \mathrm{~m}$ x $50 \mathrm{~m}$ plots. A $50 \mathrm{~m}$ measuring tape was laid out along the plot center in a south-north direction. All woody stems within a plot and having a height greater than $1.5 \mathrm{~m}$ were identified by species and had their diameter at $1.3 \mathrm{~m}$ height $(\mathrm{dbh})$ measured. Fine litter plots of $50 \mathrm{~cm}$ x $50 \mathrm{~cm}$ were located along the measuring tape at start $(0 \mathrm{~m})$, middle $(25 \mathrm{~m})$ and at end of tape $(50$ m) mark. In each litter plot, all live and dead grass, herbs, fallen leaf matter and small branches $(<10 \mathrm{~mm}$ width) were collected and stored in paper bags. These were later oven dried and weighed to estimate fuel biomass. Soil characteristics were determined by taking samples at opposite quadrants in each $50 \mathrm{~m} \mathrm{x} 50 \mathrm{~m}$ plot using a soil auger. Soil from the top $30 \mathrm{~cm}$ of the profile was taken, mixed and moistened to determine soil texture. Soil depth was estimated by driving the soil auger until a rock or hard pan was encountered or up to a depth of one meter. Data required for running EDS include: (1) individual species growth attributes; (2) soil texture, estimated soil depth and depth at which mottling is visible; (3) species list and diameter measurements of individual stems; (4) long-term local climate data, monthly temperature and rainfall; and 5) fuel biomass estimates. Historical monthly rainfall and mean temperature for 50 consecutive years were obtained from the nearest BOM weather recording site at Mitchell Post Office.

\subsection{Landholder's tree retention preference}

In order to assess landholder's expectation of the necessary intensity of thinning that would deliver suitable vegetation cover to allow favourable grazing condition; the landholder indicated the tree stems he would prefer to retain. This information was gathered in four of the sampled plots.

\subsection{Data analysis}

Data for each plot were collated as stipulated in the Code to determine whether vegetation thickening could be demonstrated. Trees that could be removed by thinning, and the 75 immature stems that needed to be retained, were identified. Starting with the structure resulting from this virtual thinning, each plot was projected for a period of 30 years and for 50 times (iterations). At the end of a 30 year-period the results from the 50 iterations were averaged to provide statistics of projected characteristic of individual species and for the whole plot. Two scenarios were projected: (1) retaining 75 immature stems; and (2) retaining a stand structure that would ensure a sustainable species composition and tree size structure. EDS was also used to examine the potential use of fire in post-thinning management of the site to reduce the rate of vegetation thickening. 


\section{RESULTS AND DISCUSSION}

\subsection{Demonstrating increased vegetation density}

The average number of immature stems in the five plots was 287 stems in a 0.25 ha area (Table 1). This count was higher than the minimum number of immature stems (250 stems) stipulated in the acceptable solution that defines when thinning can occur. Since the current stem density of immature stems is approximately 1200 stems ha $^{-1}$ and the required number of immature stems to be retained is 300 stems ha $^{-1}$, a thinning operation could remove about 900 stems $\mathrm{ha}^{-1}$.

Table 1. Summary of data collected in five $50 \mathrm{~m} \times 50 \mathrm{~m}$ field plots showing the numbers of mature and immature trees for the two species categories in each plot, diameter (dbh) limits and number of dead trees.

\begin{tabular}{|c|c|c|c|c|c|c|}
\hline \multirow[t]{2}{*}{ Plot } & \multicolumn{2}{|c|}{ Eucalyptus species } & \multicolumn{2}{|c|}{ Other species } & \multirow{2}{*}{$\begin{array}{c}\text { Total } \\
\text { immature } \\
\text { stems }\end{array}$} & \multirow{2}{*}{$\begin{array}{l}\text { Dead } \\
\text { stems }\end{array}$} \\
\hline & $\begin{array}{c}\text { Mature }>30 \\
\mathrm{~cm} \mathrm{dbh}\end{array}$ & $\begin{array}{c}\text { Immature }<30 \\
\mathrm{~cm} \mathrm{dbh}\end{array}$ & $\begin{array}{c}\text { Mature }>20 \\
\mathrm{~cm} \mathrm{dbh}\end{array}$ & $\begin{array}{c}\text { Immature }<20 \\
\mathrm{~cm} \mathrm{dbh}\end{array}$ & & \\
\hline 1 & 7 & 26 & 1 & 263 & 289 & 26 \\
\hline 2 & 11 & 17 & 9 & 226 & 243 & 8 \\
\hline 3 & 7 & 9 & 23 & 260 & 269 & 28 \\
\hline 4 & 7 & 24 & 12 & 287 & 311 & 6 \\
\hline 5 & 6 & 5 & 9 & 319 & 324 & 4 \\
\hline Averages & 8 & 16 & 11 & 271 & 287 & 14 \\
\hline
\end{tabular}

\subsection{Diameter size class structure and species composition of the forest}

Figure 1 shows the tree diameter size structure of the sampled sites. Plots 1,2 and 5 had a generally unimodal distribution characterized by higher density of trees within the $2-20 \mathrm{~cm}$ dbh range and few stems in the $<2 \mathrm{~cm}$ and in the $>20 \mathrm{~cm}$ dbh sizes. The tree size class structure in Plots 3 and 4 showed a decay distribution characterized by high density of younger trees and a decline with increase in diameter sizes with an exception of low density of stems in the $<2 \mathrm{~cm}$ dbh range in Plot 4. Species composition of Plot 1 was dominated by Eremophila mitchellii. In plots 2, 3, 4 and 5, Eremophila mitchellii and Callitris glaucophylla had strong representation forming more than $75 \%$ of stem counts for trees with $\mathrm{dbh}<10 \mathrm{~cm}$. The high density of individual stems in the $0-2 \mathrm{dbh}$ class in Plot 3 is attributed to the multi-stem shrubby growth habit of Hovea longipes that dominated the site.

\subsection{Landholder's stem and species retention preference}

The number of stems retained using landholder selection preference ranged from 22 to 51 stems in a 0.25 ha area (Figure 1, plots 2, 3, 4,5). These totals included all stems of all sizes and were therefore significantly lower than the minimum recommended retention rate for immature stems (75 stems). The landholder preference included removal of large quantities of the key defining species for the regional ecosystem and would potentially lead to loss of species diversity. For example, in Plot 2 only few stems of the defining species (Eucalyptus populnea and Eremophila mitchellii) would be retained. At least 5 species would be completely removed (Species data not shown). Similarly, in Plot 5 the quantity of Acacia harpophylla and Eremophila mitchellii that was proposed for removal was approximately $95 \%$ of the current density. This would completely alter the stand structure and species composition of the site. Nevertheless, looking at the diameter distributions (Figure 1), the landholder's preference was consistent with retaining large trees and removing the bulk of the re-growth. Clearly, the landholder's retention strategy did not suggest consideration of structure of the retained vegetation in terms size class distribution and species diversity.

\subsection{Projecting future vegetation development}

The current and future development of a typical $50 \mathrm{~m} \times 50 \mathrm{~m}$ plot at the study site is presented in Figure 2 using data collected from Plot 4. Current structural characteristics of the plot indicated dominance of Eremophila mitchellii and Callitris glaucophylla among the small dbh sizes $(<20 \mathrm{~cm})$, very low stem counts in the $0-2 \mathrm{~cm}$ dbh class indicating poor recruitment of most species. There was minimal or no recruitment of the upper canopy species (mainly Eucalyptus populnea and Eucalyptus melanophloia) (Figure 2a). A 30-year projection starting with current vegetation structure (Figure 2a) suggests that vegetation thickening is likely to occur in future with Eremophila mitchellii and Callitris glaucophylla dominating the sites. 

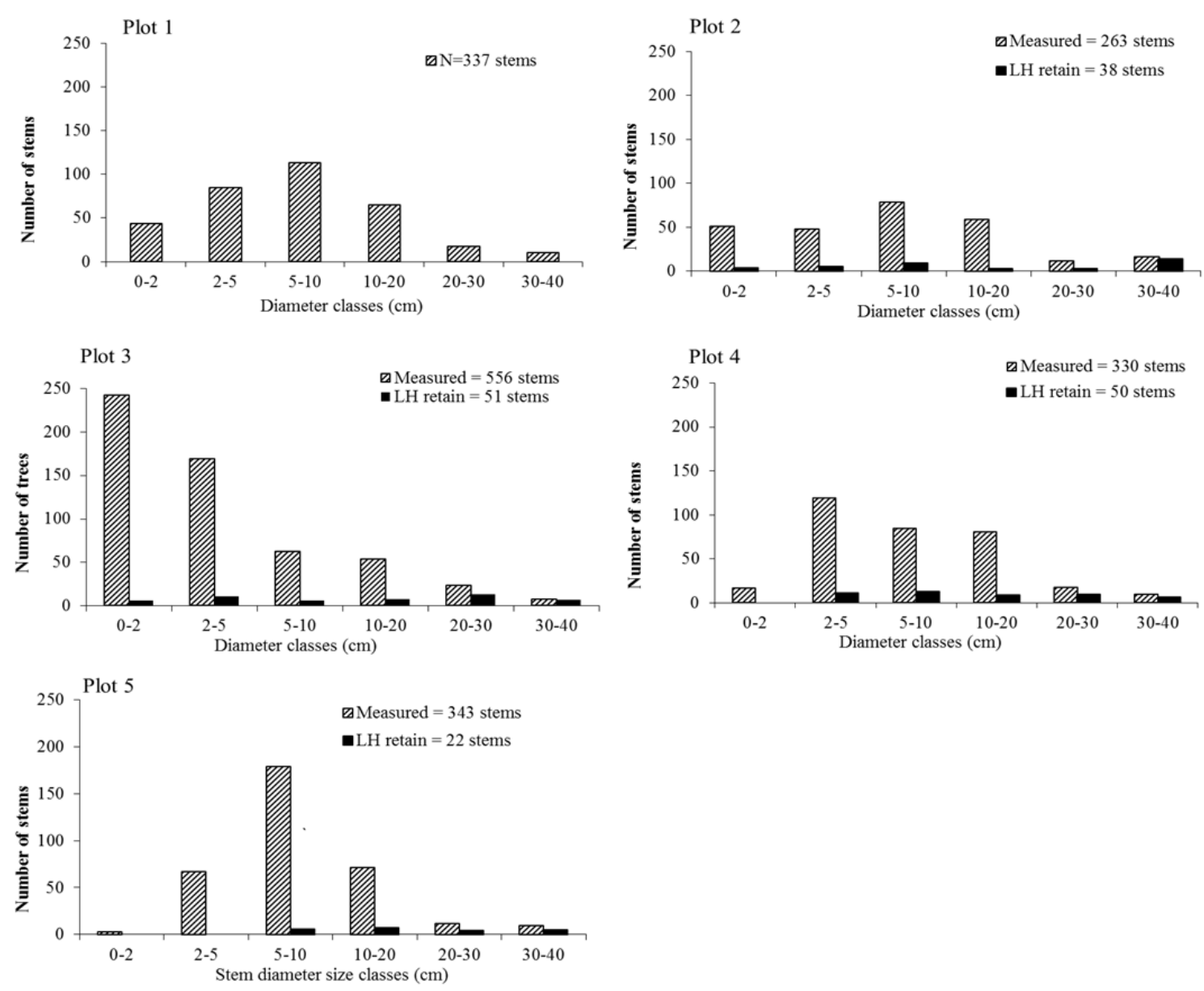

Figure 1. Observed stem diameter size class distribution for each plot with plots 2, 3, 4 and 5 showing proposed retention density based on landholder's $(\mathrm{LH})$ preference.

Several large stems of Eucalyptus populnea persisted over the 30-year projection period. Eremophila mitchellii and Callitris glaucophylla continued to dominate the $<20 \mathrm{~cm}$ dbh sizes. Increased recruitment of Geijera parviflora is projected to occur within the time frame (Figure $2 b$ ).
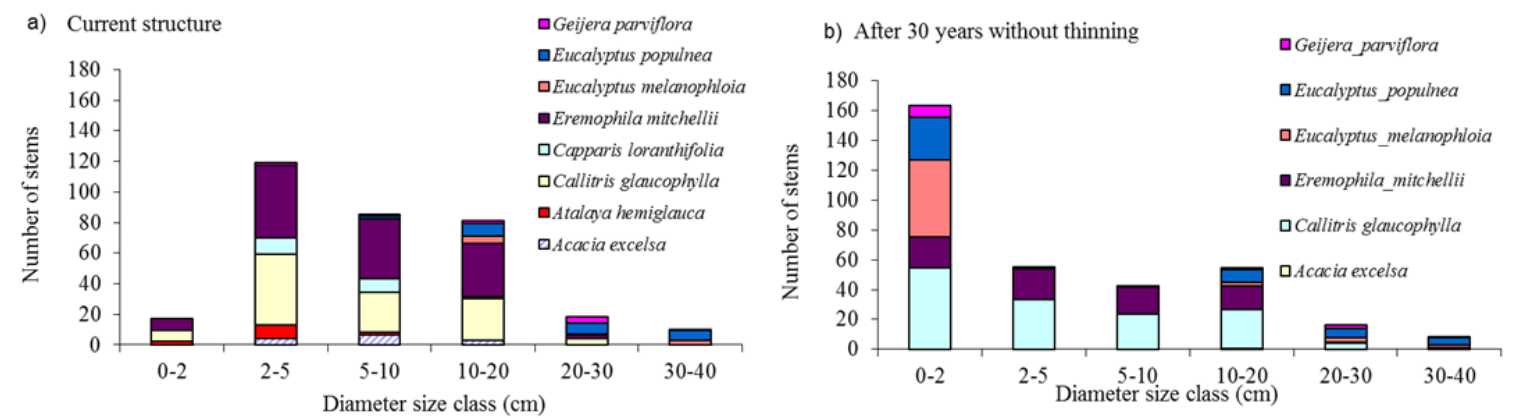

Figure 2. The observed and projected (30 years) floristic composition and stem size structure for Plot 4 before thinning 


\subsection{Conserving the remnant regional ecosystem if a thinning is done}

In order to conserve a mapped regional ecosystem, the vegetation management Code requires that thinning must maintain the natural floristic composition and range of dbh sizes of each species, while retaining all mature trees. The structure category of Plot 4 is described as Sparse, hence a minimum number of 75 immature stems must be retained in a 0.25 ha area. In the context of a nature refuge and slow growth rates of upper canopy species (Eucalyptus populnea), the potential loss of biodiversity values both in the short and long term needed to be carefully evaluated. Hence two thinning scenarios were considered: (1) thinning that retained the minimum number of immature stems (75) according to the Code; and (2) thinning that retained more immature stems (140) to compensate for potential mortality losses and slow growth rates inherent at the locality. The initial structure for the retention of 75 and 140 stems is presented in Figure 3 a showing that almost twice as many stems were retained within 2 to $20 \mathrm{~cm}$ dbh size classes in the 140 -stems scenario. Cognisant of the small numbers of Eucalyptus populnea and E. melanophloia stems within the immature diameter sizes, all stems of these two species were retained. Hence the difference between the 75 and 140 stems-retention scenarios is the number and distribution of immature stems of other species while maintaining the floristic composition of the regional ecosystem.
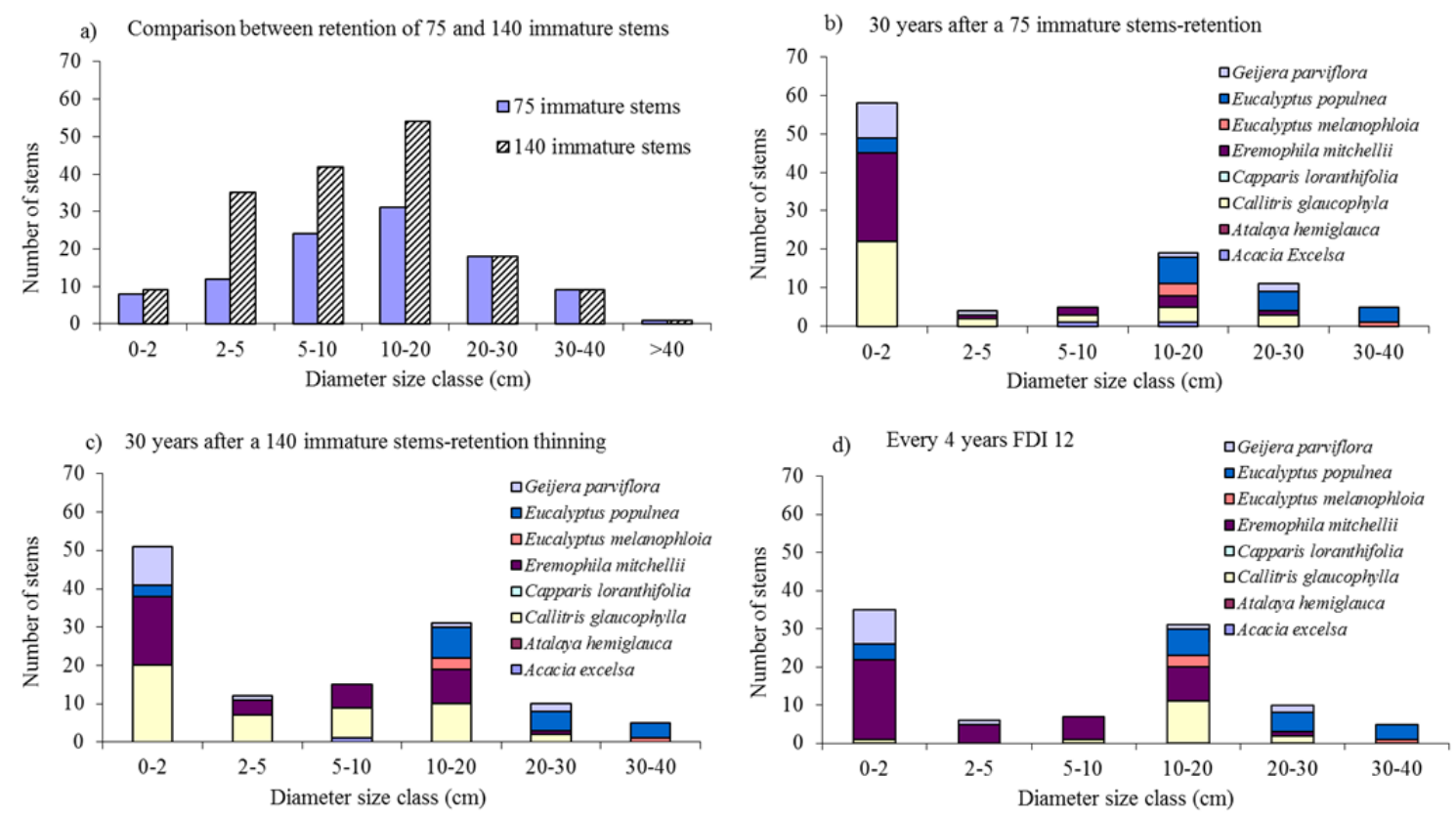

Figure 3. Comparison between 75 and 140 immature stem retention scenarios, their projected floristic composition and stem sizes after 30 years and a proposed fire regime with a fire danger index (FDI) of 12.

A 30-year projection scenario retaining 75 immature stems suggested some recruitment of the four main species comprising the regional ecosystem (Figure 3b). However the slow growth rate which was driven by the relatively dry conditions, limited the rate of replacement of dying stems. Floristic composition of the regional ecosystem was retained and the large and well established stems were mostly intact. However the number of trees at the site had dwindled because of deaths of the more abundant and relatively short-lived species in the low tree layer. A 30-year projection of the 140 stems-retention scenario suggested a similar pattern of tree recruitment and floristic composition to that of the 75 stems-retention but with relatively more trees in $<20 \mathrm{~cm}$ dbh size class providing a more resilient stand structure (Figure $3 \mathrm{c}$ ).

\subsection{Managing increasing tree density}

As indicated by the high number of recruits projected in the $0-2 \mathrm{~cm}$ dbh size class in Figures $3 \mathrm{~b}$ and $3 \mathrm{c}$, woody vegetation density is likely to increase in future if there is no treatment. To counteract this tendency a management strategy that will reduce the number of recruits of targeted species while allowing recruitment of species that are represented in the regional ecosystem overstorey structure is required. Management options might include burning, grazing management, maintaining perennial groundcover to ensure competition, and use of herbicides. However effective management strategies for saplings need to target them before their height growth escapes the flame height from a cool burn 
The potential use of fire as a management tool was investigated using EDS. Effective use of fire requires careful planning and the accumulation of a requisite fuel load. This results in forfeited grazing and loss of short-term income. Based on data collected from the nature refuge during this study, fine litter fuel load ranged from 4.2 to 15 tonnes per hectare, which is sufficient to carry a fire.

Several fire regimes and their long term (30 years) impact on the floristic and tree size class characteristics were examined. A controlled burning regime with a 4-year fire frequency and a McArthur Fire Danger Index (FDI) of less than 12 (McArthur, 1973) provided promising results (Figure 3d). The 4-year fire frequency enabled fuel load accumulation sufficient to carry a fire which is likely to kill most stems of Callitris glaucophylla $<10 \mathrm{~cm}$ dbh and some stems of Eremophila mitchellii despite its resistance to fire.

Analyses of forest structural change using EDS have demonstrated that local growing condition has a strong bearing on the rate of tree growth and ability to replenish dwindling structural classes. Growth rates and survival of new saplings at Mt Armour were low, suggesting that the observed vegetation thickening has taken many decades. This growth response has great implications when considering thinning retention rates. Comparison between 75 and 140 stems retention scenarios suggested that a 75 stems retention scenario is a high risk option for a nature refuge compared to a 140 stem retention scenario. With so few stems progressing to higher diameter classes in 30-year period (Figure $3 \mathrm{~b}$ and $3 \mathrm{c}$ ), any loss or death of immature stems may impact on the basic floristic and structural characteristics of the forest.

This study has demonstrated the useful role that growth simulation can play in supporting long-term decisions. The study did not factor-in potential changes in weather attributes associated with global climate change. However predicted rainfall and temperature can be easily incorporated while running the model. It was assumed that livestock stocking is kept at site carrying capacity level. It is recommended that more plots be measured to capture vegetation variability within the entire nature refuge.

\section{Acknowledgements}

The contribution of Tony Bean (Qld herbarium), Tanya Pritchard and Brett Galloway (Nature Refuge, Southern region) and the landholders Gill and Eunice Campbell in collecting the field data is acknowledged. Peer reviews of this manuscript provided by Bruce Wilson and John Neldner are gratefully acknowledged.

\section{REFERENCES}

Botkin, D.B., 1993. Forest Dynamics: An Ecological Model. Oxford University Press Inc., New York.

Botkin, D.B., Janak, J.F., Wallis, J.R., 1972. Some ecological consequences of a computer model of forest growth. J. Ecol. 60, 849-873.

DNRM, 2012. Regional Vegetation Management Code for Brigalow Belt and New England Tablelands Bioregions In. Department of Natural Resources and Mines, Queensland Government, Brisbane, pp. http://www.nrm.qld.gov.au/vegetation/pdf/brigalow-code-nov-2012.pdf. Accessed June 2013.

Gifford, R.M., Howden, M., 2001. Vegetation thickening in an ecological perspective: significance to national greenhouse gas inventories. Environmental Science \& Policy 4, 59-72.

Houghton, R.A., Hackler, J.L., Lawrence, K.T., 2000. Changes in terrestrial carbon storage in the United States. 1: the roles of fire and fire management Glob. Ecol. Biogeogr. 9, 145-170.

McArthur, A.G., 1973. Forest Fire Danger Meter Mark5. In. CSIRO Forestry and Forest Products, Bushfire behaviour and management.

Ngugi, M.R., Botkin, D.B., 2011. Validation of a multispecies forest dynamics model using 50-year growth from Eucalyptus forests in eastern Australia. Ecol. Model. 222, 3261-3270.

Ngugi, M.R., Botkin, D.B., Doley, D., Cant, M., Kelley, J., 2013. Restoration and management of Callitris forest ecosystems in eastern Australia: simulation of attributes of growth dynamics, growth increment and biomass accumulation. Ecol. Model. 263, 152-161.

Ngugi, M.R., Johnson, R.W., McDonald, W.J.F., 2011. Restoration of ecosystems for biodiversity and carbon sequestration: Simulating growth dynamics of brigalow vegetation communities in Australia. Ecol. Model. 222, 785-794.

Ngugi, M.R., Jones, B., Karabut, S., 2007. Ecosystem Dynamics Simulator: A powerful predictive tool for vegetation management and restoration (Queensland, Australia). Ecological Restoration 25, 69-70.

Phillips, O.L., Malhi, Y., Higuchi, N., Laurance, W.F., Nunez, P.V., Vasquez, R.M., Laurance, S.G., Ferreira, L.V., Stern, M., Brown, S., Grace, J., 1998. Changes in carbon balance of tropical forests:Evidence from long term plots. Science 282, 439442.

Porte, A., Bartelink, H.H., 2002. Modelling mixed forest growth: a review of models for forest management. Ecol. Model. 150, 141-188.

Scott, R.L., Huxman, T.E., Williams, D.G., Goodrich, D.C., 2006. Ecohydrological impacts of woody-plant encroachment: seasonal patterns of water and carbon dioxide exchange within a semiarid riparian environment. Global Change Biology 12, 311-324.

Shugart, H.H., 1984. A Theory of Forest Dynamics. Springer-Verlag Inc., New York.

Shugart, H.H., 2002. Forest gap models. In: Mooney, H.A., Canadell, J.G. (Eds.), The Earth system: biological and ecological dimensions of global environmental change. John Willey \& Sons, Ltd, Chichester, pp. 316-323.

SoE, 2011. Australia State of the Environment 2011 In. Department of Sustainability, Environment, Water, Population and Communities, Australian Government.

VMA, Q., 1999. Vegatation Mangement Act. In: Mines, D.o.N.R.a. (Ed.). Queensland Government.

Witt, G.B., Harrington, R.A., Page, M.J., 2009. Is vegation thickenning' occurring in Queensland's mulga lands - a 50-year aerial photographic analysis. Aust. J. Bot. 57, 572-582 